\title{
Dilute Surfactant Methods for Carbonate Formations
}

ID Number: DE-FC26-02NT 15322

Quarterly Progress Report

Reporting Period Start Date: 10-1-2003

Reporting Period End Date: 12-31-2003

Submitted to the

U.S. Department of Energy

Kishore K. Mohanty

Department of Chemical Engineering

University of Houston

4800 Calhoun Road

Houston, Texas 77204-4004

January, 2004 


\section{Disclaimer}

This report was prepared as an account of work sponsored by an agency of the United States Government. Neither the United States Government nor any agency thereof, nor any of their employees, makes any warranty, express or implied, or assumes any legal liability or responsibility for the accuracy, completeness, or usefulness of any information, apparatus, or process disclosed, or represents that its use would not infringe privately owned rights. Reference herein to any specific commercial product, process, or service by trade name, trademark, manufacturer, or otherwise does not necessarily constitute or imply its endorsement, recommendation, or favoring by the United States Government or any agency thereof. The views and opinions of authors expressed herein do not necessarily state or reflect those of the United States Government or any agency thereof. 


\begin{abstract}
There are many carbonate reservoirs in US (and the world) with light oil and fracture pressure below its minimum miscibility pressure (or reservoir may be naturally fractured). Many carbonate reservoirs are naturally fractured. Waterflooding is effective in fractured reservoirs, if the formation is water-wet. Many fractured carbonate reservoirs, however, are mixed-wet and recoveries with conventional methods are low (less than 10\%). Thermal and miscible tertiary recovery techniques are not effective in these reservoirs. Surfactant flooding (or huff-n-puff) is the only hope, yet it was developed for sandstone reservoirs in the past. The goal of this research is to evaluate dilute (hence relatively inexpensive) surfactant methods for carbonate formations and identify conditions under which they can be effective. Anionic surfactants (SS-6656, Alfoterra 35, 38, 63,65,68) have been identified which can change the wettability of the calcite surface to intermediate/water-wet condition as well or better than the cationic surfactant DTAB with a West Texas crude oil in the presence of $\mathrm{Na}_{2} \mathrm{CO}_{3}$. All the carbonate surfaces (Lithographic Limestone, Marble, Dolomite and Calcite) show similar behavior with respect to wettability alteration with surfactant 4-22. Anionic surfactants (5-166, Alfoterra-33 and Alfoterra-38 and Alfoterra-68), which lower the interfacial tension with a West Texas crude oil to very low values $\left(<10^{-2} \mathrm{nM} / \mathrm{m}\right)$, have also been identified. Plans for the next quarter include conducting wettability, mobilization, and imbibition studies.
\end{abstract}




\section{TABLE OF CONTENTS}

Page

Cover Page $\quad 1$

Disclaimer 2

$\begin{array}{ll}\text { Abstract } & 3\end{array}$

$\begin{array}{ll}\text { Table of Contents } & 4\end{array}$

$\begin{array}{ll}\text { Executive Summary } & 6\end{array}$

$\begin{array}{ll}\text { Introduction } & 7\end{array}$

Experimental $\quad 8$

Results and Discussion 11

$\begin{array}{ll}\text { Technology Transfer } & 16\end{array}$

$\begin{array}{ll}\text { Conclusions } & 16\end{array}$

Plans for Next Reporting Period 17

$\begin{array}{ll}\text { References } & 18\end{array}$

$\begin{array}{ll}\text { Tables } & 19\end{array}$ 


\section{List of Graphical Materials}

Page

Fig. 1a - Phase behavior of oil and water for varying concentrations of $\mathrm{Na}_{2} \mathrm{CO}_{3}$ with no surfactant at WOR $=1$.

Fig. $1 \mathrm{~b}-$ Phase behavior of oil and water for varying concentrations of $\mathrm{Na}_{2} \mathrm{CO}_{3}$ with $0.05 \mathrm{wt} \%$ 5-166 surfactant at WOR $=1$.

Fig. $1 \mathrm{~b}-$ Phase behavior of oil and water for varying concentrations of $\mathrm{Na}_{2} \mathrm{CO}_{3}$ with $0.05 \mathrm{wt} \%$

Alfoterra-38 surfactant at WOR $=1$.

Fig. $2 \mathrm{a}-$ IFT of crude oil with $0.05 \mathrm{wt} \%$ sulfonate surfactants and with $\mathrm{Na}_{2} \mathrm{CO}_{3}$ alone. 20

Fig. $2 b-$ IFT of crude oil with $0.05 \mathrm{wt} \%$ Alfoterra $3 \mathrm{n}$ series surfactants.

Fig. 2c - IFT of crude oil with $0.05 \mathrm{wt} \%$ Alfoterra $6 \mathrm{n}$ series surfactants.

Fig. 2d - IFT of crude oil with DTAB at varying surfactant concentrations.

Fig. 3 - Contact angles at different stages - example of 0.05 wt $\%$ SS-6566.

Fig. 4 - Images of oil drop after the oil-wet calcite plate was contacted with $0.05 \mathrm{wt} \% 5-166$ surfactant solution, an example of low IFT producing surfactant.

Fig. 5 - Different sizes of drops (1-0.1 mm) evolved during wettability experiment. 21

Fig. 6 - Post-wettability test for Alfoterra-38.

Fig. 7 - Image of the calcite plate 48 hours after $1 \mathrm{wt} \%$ DTAB solution addition.

Fig. 8 - Contact angle at the end of wettability test. 


\section{Executive Summary}

There are many carbonate reservoirs in US (and the world) with light oil and fracture pressure below its minimum miscibility pressure (or reservoir may be naturally fractured). Many carbonate reservoirs are naturally fractured. Waterflooding is effective in fractured reservoirs, if the formation is water-wet. Many fractured carbonate reservoirs, however, are mixed-wet and recoveries with conventional methods are low (less than 10\%). Thermal and miscible tertiary recovery techniques are not effective in these reservoirs. Surfactant flooding (or huff-n-puff) is the only hope, yet it was developed for sandstone reservoirs in the past. The goal of this research is to evaluate dilute (hence relatively inexpensive) surfactant methods for carbonate formations and identify conditions under which they can be effective. Anionic surfactants (SS-6656, Alfoterra 35, 38, 63,65,68) have been identified which can change the wettability of the calcite surface to intermediate/water-wet condition as well or better than the cationic surfactant DTAB with a West Texas crude oil in the presence of $\mathrm{Na}_{2} \mathrm{CO}_{3}$. All the carbonate surfaces (Lithographic Limestone, Marble, Dolomite and Calcite) show similar behavior with respect to wettability alteration with surfactant 4-22. Anionic surfactants (5-166, Alfoterra-33 and Alfoterra-38 and Alfoterra-68), which lower the interfacial tension with a West Texas crude oil to very low values

$\left(<10^{-2} \mathrm{nM} / \mathrm{m}\right)$, have also been identified. Plans for the next quarter include conducting wettability, mobilization, and imbibition studies. 


\section{Introduction}

There are many carbonate reservoirs in US (and the world) with light oil and fracture pressure below its minimum miscibility pressure (or reservoir may be naturally factured). Many carbonate reservoirs are naturally fractured. Waterflooding is effective in fractured reservoirs, if the formation is water-wet. Many fractured carbonate reservoirs, however, are mixed-wet and recoveries with conventional methods are low (less than 10\%). Thermal and miscible tertiary recovery techniques are not effective in these reservoirs. Surfactant flooding (or huff-n-puff) is the only hope (Spinler et al., 2000), yet it was developed for sandstone reservoirs in the past (Bragg et al., 1982).

The goal of this research is to evaluate dilute surfactant methods for carbonate formations and identify conditions under which they can be effective. Adsorption, phase behavior, wettability alteration, IFT gradient driven imbibition, blob mobilization at high capillary and Bond numbers will be quantified. An existing laboratory simulator will be modified to incorporate the mechanisms of surfactant transport and effective parameters will be developed to model this process in a dual porosity reservoir simulator. Field-scale simulations will be conducted to identify criteria under which dilute surfactant methods are feasible without active mobility control.

This report summarizes our results for the period of July 2003 through September 2003.

The five tasks for the project are: (1) Adsorption, (2) Wettability alteration, (3) Gravity and viscous mobilization, (4) Imbibition, and (5) Simulation. The second and third tasks were worked on this quarter. The results of phase behavior and wettability are highlighted in this report. 


\section{Experimental}

\section{Material}

The properties of the surfactants evaluated are listed in Table 1. Surfactants 4-22, 5-166 and S6566 provided by Oil Chem are alkyl aryl sulphonates (two of them were ethoxylated) and the Alfoterra series provided by Sasol are alkyl propoxylated sulfates. In the nomenclature Alfoterra-mn, the second digit n (e.g., 5 in Alfoterra-35) indicates the number of propoxy groups present. Alfoterra-3n series has a carbon chain length of 14 and Alfoterra-6n series has a carbon chain length of 12-13. Of the ten surfactants evaluated one of them is a cationic surfactant, Dodecyl trimethyl ammonium bromide (DTAB), used as a reference. Surfactants were used as supplied.

Calcite (Iceland spar), lithographic limestone, marble, and dolomite plates were supplied by Scientific Ward. Synthetic calcite powder, consisting of $5 \mu \mathrm{m}$ particles, was supplied by AESAR (Johnson Mathey Inc.). The surface area for the calcite powder is $1.67 \mathrm{~m}^{2} / \mathrm{g}$. The oil was from a West Texas fractured carbonate field (supplied by Marathon Oil Company). It had 28.2 ${ }^{\circ}$ API, $19.1 \mathrm{cp}$ viscosity, 0.2 acid number and 1.17 base number. It was similar to the oil MY3 used by Hirasaki and Zhang (2003). Reformulated reservoir brine (Table 2) was used for the evaluation of the cationic surfactant. Synthetic brine composed of $\mathrm{Na}_{2} \mathrm{CO}_{3}$ was used for the anionic surfactants to lower adsorption and surfactant requirement. Ideally, the reservoir brine should have been used. However, the reservoir brine consists of divalent ions that are likely to precipitate in the presence of $\mathrm{Na}_{2} \mathrm{CO}_{3}$. In the actual field conditions, the problem is less severe because the brine is in equilibrium with the mineral rock and addition of more $\mathrm{CO}_{3}{ }^{2-}$ in fact suppresses the $\mathrm{Ca}^{2+}$ in the brine. In a study on the chemical composition during chemical flooding, Cheng (1986) found significantly lower ion exchange and mineral dissolution in the 
presence of $\mathrm{Na}_{2} \mathrm{CO}_{3}$ as compared to caustic and sodium silicate. Further, the permeability reduction due to precipitation was also found to be the lowest for $\mathrm{Na}_{2} \mathrm{CO}_{3}$.

\section{Phase Behavior Study}

Dilute solutions of anionic surfactants $(0.05$ active $\mathrm{wt} \%)$ were prepared with varying concentrations of sodium carbonate $\left(\mathrm{Na}_{2} \mathrm{CO}_{3}\right)$. These solutions were equilibrated with equal volumes of oil on a tube shaker for a period of two days. Thereafter the tubes were removed and left to settle for a day. The number of phases and the color of the phases were observed, which indicated the shift from Winsor type II- to type II+ phase behavior with the increase in salinity of the solution.

\section{Interfacial Tension Measurement}

The IFT between the equilibrated brine and oil phases was measured with help of a spinning drop tensiometer. The equilibrated brine solutions and the equilibrated oil from the phase behavior study were used to determine the interfacial tension between the synthetic brine and oil. This led to the identification of the region of lowest interfacial tension or optimum salinity of the given system. The subsequent wettability experiments were performed at the optimum salinity obtained from these measurements.

\section{Wettability Test}

The wettability tests were done on mineral plates $(2 \mathrm{~cm} \times 1 \mathrm{~cm} \times 0.2 \mathrm{~cm})$. The plates were polished on a 600 mesh diamond lap and equilibrated with synthetic brine for a day. The initial wettability state of the plate was determined by measuring the advancing and recently receded contact angle of oil with the plate immersed in brine. The plate was removed from brine and aged with oil at an elevated temperature $\left(\sim 80^{\circ} \mathrm{C}\right)$ in the oven for about two days to make it oil- 
wet. The reservoir temperature is close to the room temperature $\left(\sim 30^{\circ} \mathrm{C}\right)$, but the elevated temperature aging is done to compensate for the short aging time (compared with the geological time). After removing from the oven, the plate (with oil stuck around it) was contacted with synthetic (sodium carbonate) brine for an hour and the advancing contact angle was measured. The contact angle measurements were made with the help of a Kruss goniometer. Thereafter, the synthetic brine was replaced by the surfactant-brine solution and the evolution of contact angle was studied for a period of two days by imaging the drops attached to the plate. In the cases where the drops were too small $(<<0.1 \mathrm{~mm})$, it was difficult to measure an accurate contact angle and a post-wettability test was performed. In the post-wettability test, the plate was washed with brine following the surfactant treatment. This plate was then placed in the brine solution and an oil drop was deposited on the bottom of the surface with the help of an inverted needle (oil drops did not attach to the top of the plate in these cases). The contact angle was then measured. This gave the final wettability state of the plate. Drops were deposited on several parts of the plate and the range of the contact angles was noted. For the cationic surfactant, a similar procedure was followed except that the reformulated field brine replaced the synthetic brine. 


\section{Results and Discussion}

\section{Phase Behavior}

Fig. 1 shows the phase behavior of crude oil - brine $\left(\mathrm{Na}_{2} \mathrm{CO}_{3}\right)$ - surfactant system for three typical cases. Water-oil ratio is kept at 1:1 in all cases shown. Fig. 1(a) shows the phase behavior without addition of any synthetic surfactant, i.e., crude oil - $\mathrm{Na}_{2} \mathrm{CO}_{3}$ brine. The number underneath each test tube specifies the $\mathrm{Na}_{2} \mathrm{CO}_{3}$ concentration in the brine. Two phases (aqueous and oleic) are seen in this case. As the alkali concentration increases, the bottom (aqueous) phase first becomes darker and then clarifies beyond an alkali concentration of $0.15 \mathrm{M} . \mathrm{Na}_{2} \mathrm{CO}_{3}$ reacts with some of the napthenic acid molecules in the crude oil to make in situ surfactants. Some of these surfactants solubilize in the brine and make micelles. These micelles can solubilize some oil into the aqueous phase giving it a darker color. $\mathrm{As} \mathrm{Na}_{2} \mathrm{CO}_{3}$ in brine increases, the solubility of the surfactants in brine decreases (because of high salinity); the surfactants partition back to the oleic phase. Thus the aqueous phase clarifies above a certain $\mathrm{Na}_{2} \mathrm{CO}_{3}$ concentration.

Fig. 1(b) shows the phase behavior typical of sulphonate surfactants studied. The concentration of the surfactant 5-166 is kept constant at $0.05 \mathrm{wt} \%$ and the $\mathrm{Na}_{2} \mathrm{CO}_{3}$ concentration is increased from 0 to $0.6 \mathrm{M}$. As the caustic concentration increases, the darkness of the aqueous phase increases, reaches a maximum and then decreases. In this case, the aqueous phase is observed to be the darkest at a $\mathrm{Na}_{2} \mathrm{CO}_{3}$ concentration of $0.2 \mathrm{M}$. An optimal salinity is defined in the next section on the basis of the lowest water-oil interfacial tension; $0.2 \mathrm{M}$ salinity is close to the optimal. A small, middle phase microemulsion is also observed in the near-optimal region. Since we are operating at a very dilute surfactant concentration $(0.05 \mathrm{wt} \%)$ the middle-phase microemulsion layer formed is very thin, too small for any analysis. The aqueous phase becomes clear at the $\mathrm{Na}_{2} \mathrm{CO}_{3}$ concentration of $0.4 \mathrm{M}$ indicating Winsor type $\mathrm{II}+$ microemulsion. At this point, the system is in the over-optimum salinity regime. 
Fig. 1(c) shows the phase behavior typical of propoxylated sulfate surfactants. The concentration of the surfactant Alfoterra-38 is kept constant at $0.05 \mathrm{wt} \%$ and the $\mathrm{Na}_{2} \mathrm{CO}_{3}$ concentration is increased from 0 to $0.5 \mathrm{M}$. Again, as the alkali concentration increases, the darkness of the aqueous phase increases, reaches a maximum and then decreases. The third phase is more distinct in this case at $\mathrm{Na}_{2} \mathrm{CO}_{3}$ concentrations of $0.25 \mathrm{M}$ and $0.3 \mathrm{M}$.

\section{Interfacial Tension}

Fig. 2 shows the interfacial tension (IFT) between the aqueous and the oleic phases as a function of $\mathrm{Na}_{2} \mathrm{CO}_{3}$ concentration in these crude oil - brine $\left(\mathrm{Na}_{2} \mathrm{CO}_{3}\right)$ - surfactant systems. Water-oil ratio is again kept at 1:1 in all cases shown. The anionic surfactant concentration is also kept constant at $0.05 \mathrm{wt} \%$ in Fig. 2 (a-c) except for the case with no surfactant.

The IFT of the crude oil - brine $\left(\mathrm{Na}_{2} \mathrm{CO}_{3}\right)$ system is shown in Fig. 2(a). As the caustic concentration increases, the IFT decreases to slightly below $10^{-1} \mathrm{mN} / \mathrm{m}$ at $0.2 \mathrm{M}$ and then increases. The presence of the in situ surfactants in the aqueous phase is responsible for the decrease in IFT. Optimal salinity is defined as the salinity at the minimum IFT, i.e., $0.2 \mathrm{M}$ in this case. Fig. 2(a) also shows IFTs in crude oil - brine - surfactant systems with $0.05 \mathrm{wt} \%$ sulphonate surfactants. The ethoxylated sulphonates 4-22 and SS-6566 could lower the IFT of the system to about $10^{-2} \mathrm{mN} / \mathrm{m}$. However, amongst the three sulphonates, lowest IFT (of the order of $10^{-3} \mathrm{mN} / \mathrm{m}$ ) was obtained with surfactant 5-166, an alkyl aryl sulphonate. The lowest IFT samples corresponded to those with middle phases. Optimal salinity is about $0.2 \mathrm{M} \mathrm{Na}_{2} \mathrm{CO}_{3}$. IFTs of the order of $10^{-2} \mathrm{mN} / \mathrm{m}$ and lower are capable of mobilizing oil by buoyancy.

Fig. 2(b) shows the IFTs for the Alfoterra-3n series of propoxylated sulfate surfactants. The overall trend was similar to that of the other surfactants, i.e., the IFT decreased with increasing $\mathrm{Na}_{2} \mathrm{CO}_{3}$ concentration before reaching a minimum and then increased. The optimal salinity 
changed from 0.2 to $0.3 \mathrm{M} \mathrm{Na}_{2} \mathrm{CO}_{3}$ for the three surfactants. The minimum IFT was $10^{-3} \mathrm{mN} / \mathrm{m}$ for Alfoterra-33, $3 \times 10^{-2} \mathrm{mN} / \mathrm{m}$ for Alfoterra-35, and $9 \times 10^{-3} \mathrm{mN} / \mathrm{m}$ for Alfoterra-38. The IFT did not change monotonically with the number of propoxy groups in this series of experiments.

Fig. 2(c) shows the IFTs for the Alfoterra-6n series of propoxylated sulfate surfactants. Hydrocarbon chain length is smaller for this series of Alfoterra than the Alfoterra-3n series. The optimal salinity changed from 0.3 to $0.5 \mathrm{M} \mathrm{Na}_{2} \mathrm{CO}_{3}$ for the three surfactants. The minimum IFT was $10^{-1} \mathrm{mN} / \mathrm{m}$ for Alfoterra- $63,2 \times 10^{-2} \mathrm{mN} / \mathrm{m}$ for Alfoterra- 65 , and $7 \times 10^{-4} \mathrm{mN} / \mathrm{m}$ for Alfoterra68. The IFT decreased monotonically with the number of propoxy groups in this series of experiments.

The IFT measurements for the cationic surfactant, DTAB were carried out for varying surfactant concentrations in the field brine at a water-oil ratio of 1:1. The IFT, shown in Fig. 2(d), decreases with the increase of surfactant concentration, but reaches a plateau of about $4 \times 10^{-}$ ${ }^{2} \mathrm{mN} / \mathrm{m}$ at a surfactant concentration of $2 \mathrm{wt} \%$. At $1 \mathrm{wt} \%$ DTAB (a typical value used by Austad and Standnes, 2003), IFT is about $0.5 \mathrm{mN} / \mathrm{m}$. Thus low interfacial tension is not the mechanism for high spontaneous imbibition with $1 \mathrm{wt} \%$ DTAB solutions. Among all the surfactants studied here, low IFT $\left(<10^{-2} \mathrm{nM} / \mathrm{m}\right)$ was obtained with surfactants 5-166, Alfoterra-33 and Alfoterra-38 and Alfoterra-68. Very low tensions can be generated with anionic surfactants, but not with cationic surfactants, below a concentration of $1 \mathrm{wt} \%$.

\section{Wettability}

Wettability was evaluated by measuring water-oil contact angles. All the contact angle measurements for the anionic surfactants were made at a surfactant concentration of 0.05 active $\mathrm{wt} \%$, at the optimum salinity obtained from the IFT experiments. Fig. 3 shows the contact angles measured at different stages of the wettability experiment for the calcite plate with surfactant SS- 
6566. $0.3 \mathrm{M} \mathrm{Na}_{2} \mathrm{CO}_{3}$ solution brine was used. Before aging with oil, the mineral plate is found to be intermediate-wet with advancing contact angle greater than $90^{\circ}$ and receding contact angle less than $90^{\circ}$ (the first two points in Fig. 3). After aging the calcite plate with the crude oil at an elevated temperature for $44 \mathrm{hrs}$, the mineral plate becomes completely oil-wet with an advancing contact angle close to $160^{\circ}$ (the $3^{\text {rd }}, 4^{\text {th }}$ and $5^{\text {th }}$ points in Fig. 3). The oil-aged plate is immersed in brine and the oil-water contact line on the calcite plate is photographed to obtain this data. The brine is then replaced with a surfactant solution at its optimal salinity. When exposed to the surfactant - brine solution, (much of the oil is released from the plate) the advancing contact angle decreases with time and stabilizes at a value of about $58^{\circ}-88^{\circ}$ depending on the drop size (the last four points in Fig. 3).

Fig. 4 shows the calcite plate upper surface at different times after the oil-aged surface was exposed to the surfactant (5-166)-brine solution. The equilibrium IFT was lower than $10^{-2} \mathrm{mN} / \mathrm{m}$ for this surfactant. Oil leaves the surface because of low IFT. After 1 hour, the calcite plate does not look water-wet. The wettability was found to be in the intermediate to oil-wet state even after 48 hours (The photograph is not shown here).

The error bars on the last four points (in Fig. 3) indicate the variation of contact angle between different drops in the same experiment. Drop size is proportional to the square root of the interfacial tension and is a function of the contact angle. Fig. 5 shows the state of the calcite plate surface at the end of 48 hours for surfactant SS-6566. Drop sizes varied between $\sim 0.1 \mathrm{~mm}$ and $\sim 1 \mathrm{~mm}$. The contact angle generally increased with increasing drop size and varied between $58^{\circ}-88^{\circ}$. The wettability varies along the surface of the plate because of the nonuniformity in initial oil contact with the plate. 
In some cases, most of the oil leaves the plate within 48 hours, thus it is difficult to get a contact angle at this stage. In such cases, the plate was further washed with brine and a drop of crude oil was placed at the bottom of the plate. This contact angle is referred to as the "postwettability" test. Fig. 6 shows such an example, for $0.5 \mathrm{wt} \%$ Alfoterra-38. The contact angle is about $32^{\circ}$, and calcite plate appears water-wet in this case. The post wettability-test was conducted for Alfoterra-35, 38, 63, 65, and 68 .

Wettability tests for the DTAB were conducted with the field brine at 1 and $0.5 \mathrm{wt} \%$. Fig. 7 shows the calcite plate after 48 hours of contact with $1 \mathrm{wt} \%$ surfactant. Oil drops attached are bigger than those seen with the Alfoterra surfactants; this is a result of higher IFT. The contact angles of these oil drops are between $70^{\circ}-100^{\circ}$. For the $0.5 \mathrm{wt} \%$ surfactant solution, the contact angles were about $140^{\circ}$ (photo not shown). Thus DTAB does not change the wettability, if the concentration is small. At about $1 \mathrm{wt} \%$, wettability changes to intermediate to water-wet.

Fig. 8 shows the contact angle at the end of wettability tests (including the post wettabilitytests for Alfoterra 35, 38, 63, 65, 68) for all the surfactants studied. Amongst the sulfonates, SS6566 altered the wettability of the oil-wet carbonate surface to moderately water-wet state. Amongst the propoxylated sulfates, Alfoterra-38 changed the wettability to a near water-wet state. Except for Alfoterra-33, all other propoxylated sulphates resulted in intermediate / waterwet wettability. DTAB at $1 \mathrm{wt} \%$ also changed the wettability to intermediate / water- wet state. Lower concentrations of DTAB were not effective in changing wettability.

Effect of different carbonate surfaces on wettability alteration was studied with only one anionic surfactant 4-22 (0.05 wt $\%$ active). The four different surfaces studied were lithographic limestone, calcite, marble and dolomite. The initial state of all the mineral surfaces except for the limestone, determined after aging the surfaces in synthetic brine, was found to be intermediatewet. Lithographic limestone was found to be oil-wet. After aging the surfaces at elevated 
temperature in crude oil for two days all the surfaces exhibited close to oil-wet state. When contacted with the anionic surfactant 4-22, significant amount of oil was seen leaving the surface possibly due to lowered interfacial tension. However, the evolution of contact angles monitored over a period of two days showed that all the four mineral surfaces had been altered to an intermediate-wet state (Table 3).

\section{Technology Transfer}

Marathon oil company is one of the major producers in West Texas carbonates. We have briefed them about our project plans and have received field samples. We are working with Oil Chem Technology and Sasol on surfactants. These collaborations are extremely important to the success of our project. We have written a paper, SPE 89423 , which will be presented at the $14^{\text {th }}$ SPE/DOE IOR symposium in Tulsa, April, 2004.

\section{Conclusions}

Anionic surfactants (SS-6656, Alfoterra 35, 38, 63,65,68) have been identified which can change the wettability of the calcite surface to intermediate/water-wet condition as well or better than the cationic surfactant DTAB with a West Texas crude oil in the presence of $\mathrm{Na}_{2} \mathrm{CO}_{3}$. All the carbonate surfaces (Lithographic Limestone, Marble, Dolomite and Calcite) show similar behavior with respect to wettability alteration with surfactant 4-22. Anionic surfactants (5-166, Alfoterra-33 and Alfoterra-38 and Alfoterra-68), which lower the interfacial tension with a West Texas crude oil to very low values $\left(<10^{-2} \mathrm{nM} / \mathrm{m}\right)$, have also been identified. (Task 2$)$ 


\section{Plans for Next Reporting Period}

- Wettability measurements (Task 2)

- Mobilization experiments (Task 3)

- Imbibition experiments (Task 4) 


\section{References}

Bragg, J. R. et al.: "Loudon Surfactnat Flood Pilot Test," SPE/DOE 10862, SPE/DOE $3^{\text {rd }}$ Joint Symposium on EOR, Tulsa, April 4-7, 1982.

Spinler, E. A. et al.: "Enhancement of Oil Recovery Using Low Concentration Surfactant to Improve Spontaneous or Forced Imbibition in Chalk," SPE 59290, SPE/DOE Improved Oil Recovery Symposium, Tulsa, April 3-5, 2000.

Austad, T. and Standnes, D. C.: "Spontaneous Imbibition of Water into Oil-wet Carbonates," J. Pet. Sci. \& Eng, 39, 363-376 (2003).

Hirasaki, G. and Danhua, L.Z, "Surface Chemistry of Oil Recovery From Fractured, Oil-wet, Carbonate Formation,” SPE 80989 presented at SPE International Symposium on Oilfield Chemistry held in Houston, Texas, USA, 5-8 February, 2003.

Cheng, K.H., "Chemical Consumption during Alkaline Flooding: A Comparative Evaluation," SPE 14944 presented at the SPE/DOE Fifth Symposium on Enhanced Oil Recovery, Tulsa, OK, 20-23 April, 1986. 
Table 1 : Surfactant properties

\begin{tabular}{|c|c|c|c|c|c|}
\hline Trade name & Source & Structural name & Active \% & $\begin{array}{l}\begin{array}{l}\text { Molecular } \\
\text { Wt. }\end{array} \\
\end{array}$ & cmc(g/l) \\
\hline \multicolumn{6}{|l|}{ Sulphonates } \\
\hline $4-22$ & Oil Chem & $\begin{array}{l}\text { Alkyl aryl ethoxylated } \\
\text { sulphonated phenol }\end{array}$ & $50 \%$ & - & 0.001 \\
\hline $5-166$ & Oil Chem & Alkyl aryl sulphonate & $50 \%$ & - & 0.001 \\
\hline SS-6566 & Oil Chem & $\begin{array}{l}\text { Alkyl aryl ethoxylated } \\
\text { sulphonate }\end{array}$ & $50 \%$ & - & 0.002 \\
\hline \multicolumn{6}{|c|}{ Propoxylated sulfates, sodium salt } \\
\hline Alfoterra-33 & Sasol & Propoxylated sulfates $-3 \mathrm{PO}$ & $28.1 \%$ & 485 & 0.01 \\
\hline Alfoterra-35 & Sasol & Propoxylated sulfates $-5 \mathrm{PO}$ & $28.0 \%$ & 588 & 0.006 \\
\hline Alfoterra-38 & Sasol & Propoxylated sulfates -8PO & $26.0 \%$ & 715 & 0.005 \\
\hline Alfoterra-63 & Sasol & Propoxylated sulfates -3PO & $30.0 \%$ & 467 & 0.025 \\
\hline Alfoterra-65 & Sasol & Propoxylated sulfates- 5PO & $31.6 \%$ & 561 & 0.018 \\
\hline Alfoterra-68 & Sasol & Propoxylated sulfates -8PO & $30.6 \%$ & 667 & 0.014 \\
\hline DTAB & Sigma & $\begin{array}{l}\text { Dodecyltrimethylammonium } \\
\text { bromide }\end{array}$ & & 308.3 & 4.625 \\
\hline
\end{tabular}

Table 2

Composition of reformulated brine

\begin{tabular}{|l|c}
\hline \multicolumn{1}{|c|}{ Salt } & gm/litre \\
\hline & \\
$\mathrm{CaCl}_{2} .2 \mathrm{H} 2 \mathrm{O}$ & 2.942 \\
$\mathrm{MgCl}_{2} \cdot 6 \mathrm{H} 2 \mathrm{O}$ & 2.032 \\
$\mathrm{NaCl}$ & 5.815 \\
$\mathrm{Fe}\left(\mathrm{NH}_{4}\right)_{2}\left(\mathrm{SO}_{4}\right)_{2} \cdot 6 \mathrm{H} 2 \mathrm{O}$ & 0.007 \\
$\mathrm{Na}_{2} \mathrm{SO}_{4}$ & 0.237 \\
& \\
\hline
\end{tabular}

Table 3: Contact angles on different minerals with

Surfactant 4-22

\begin{tabular}{|l|l|l|l|l|}
\hline & Marble & Limestone & Dolomite & Calcite \\
\hline \multicolumn{5}{|l|}{ Before ageing with oil } \\
\hline Receding Angle & $44-45^{\circ}$ & $160-163^{\circ}$ & $43^{\circ}$ & $55-56^{\circ}$ \\
\hline Advancing Angle & $126-137^{0}$ & $165-168^{\circ}$ & $110-125^{\circ}$ & $110-116^{\circ}$ \\
\hline After ageing the mineral plate with oil at 80 C \\
\hline $\begin{array}{l}\text { 1. Contact with Brine } \\
\text {-after 60 mins }\end{array}$ & $132^{\circ}$ & $180^{\circ}$ & $160^{\circ}$ & $>170^{\circ}$ \\
\hline 2. Contact with surfactant & & & & \\
\hline -after 1 hour & $121^{0}$ & $161^{0}$ & $156^{\circ}$ & $145^{\circ}$ \\
\hline -after 48 hours & $146^{\circ}$ & $163^{0}$ & $141^{0}$ & $140^{\circ}$ \\
\hline
\end{tabular}




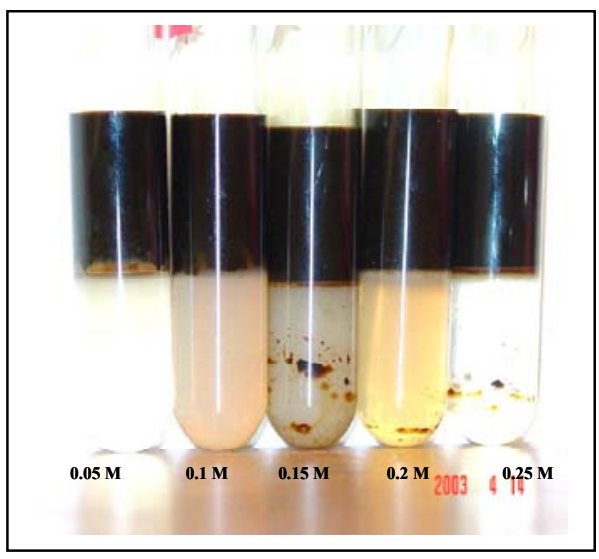

Figure 1a. Phase behavior of oil and water for varying concentration of $\mathrm{Na}_{2} \mathrm{CO}_{3}$ with no surfactant at WOR=1

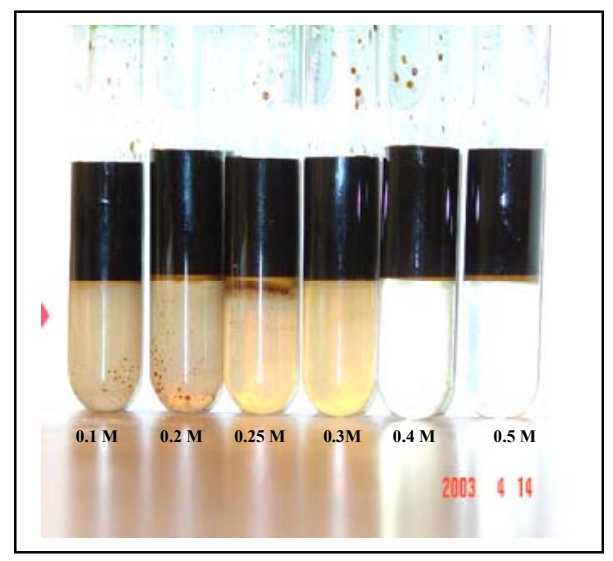

Figure 1b. Phase behavior of oil and water for varyng concentration of $\mathrm{Na}_{2} \mathrm{CO}_{3}$ with $0.05 w t \%$ 5-166 surfactant at WOR $=1$

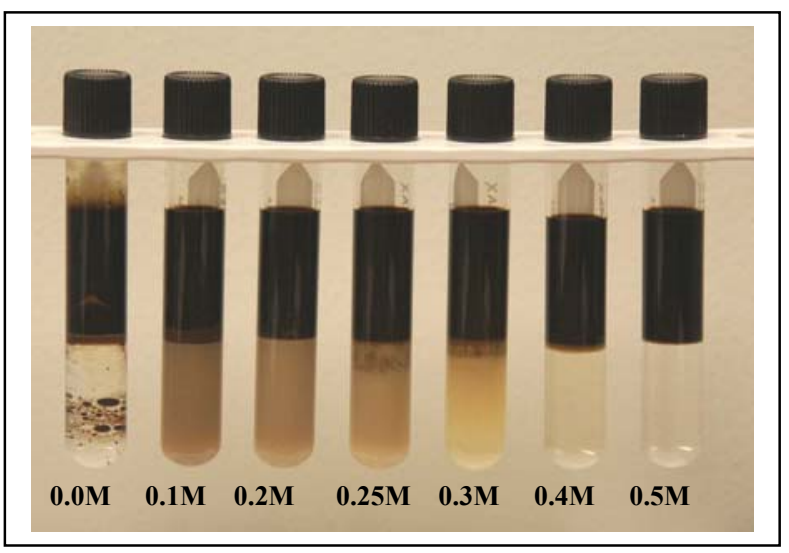

Figure 1c. Phase behavior for $0.05 w t \%$ Alfoterra-38 surfactant with varying concentration of $\mathrm{Na}_{2} \mathrm{CO}_{3}$ at $\mathrm{WOR}$ $=1$

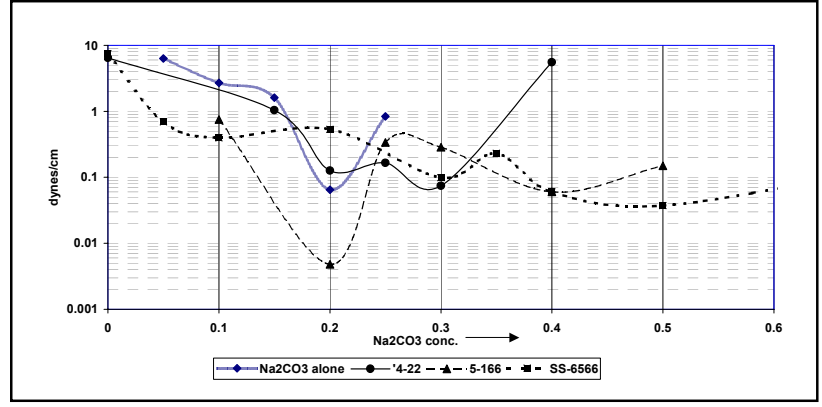

Figure 2a. IFT of crude oil with $0.05 \mathrm{wt} \%$ sulfonate surfactants and with $\mathrm{Na}_{2} \mathrm{CO}_{3}$ alone

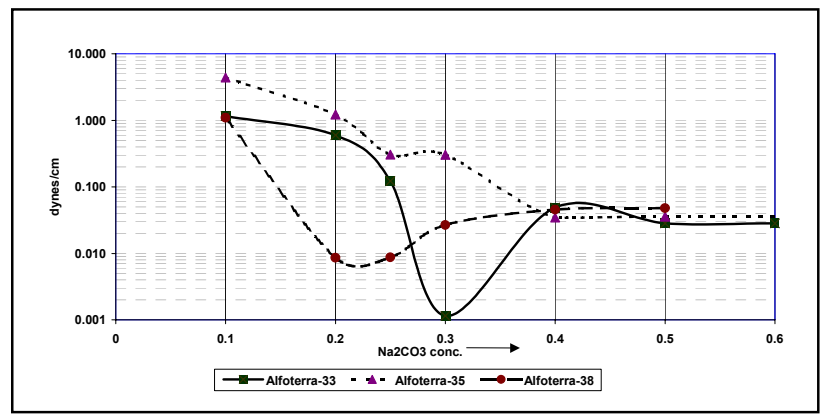

Figure 2b. IFT of crude oil with 0.05 wt $\%$ Alfoterra-3n series of surfactants

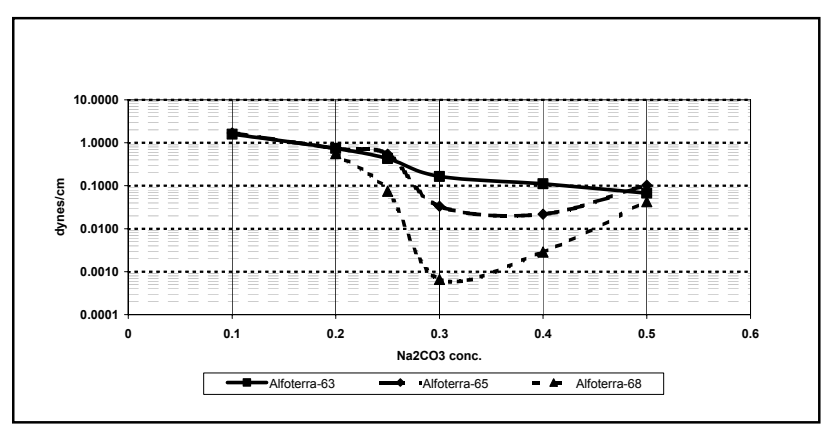

Figure 2c. IFT of crude oil with 0.05 wt $\%$ Alfoterra-6n series of surfactants

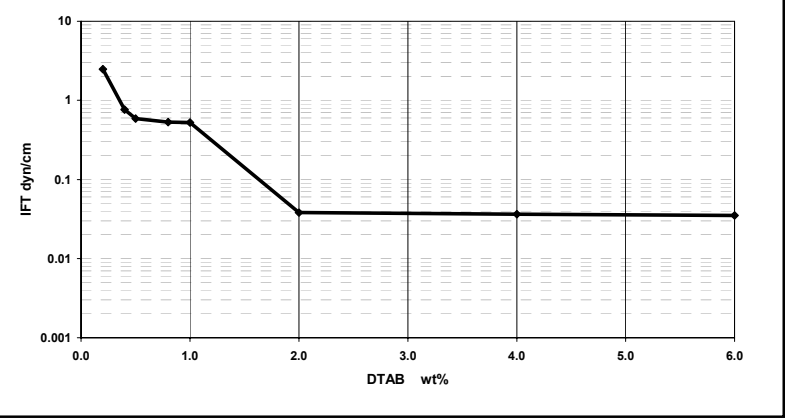

Figure 2d. IFT of crude oil with DTAB at varying surfactant concentrations. 
Figure 3. Contact angles at different stages - example of 0.05 wt $\%$ SS-6566

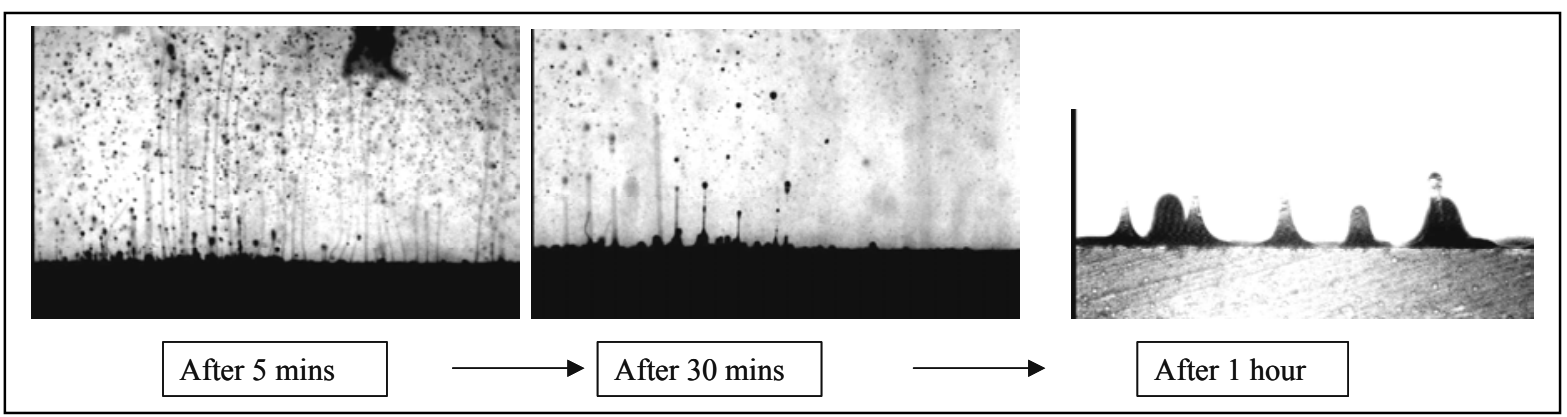

Figure 4. Images of oil drop after the oil-wet calcite plate was contacted with $0.05 \mathrm{wt} \%$ 5-166 surfactant solution, an example of a low IFT producing surfactant.

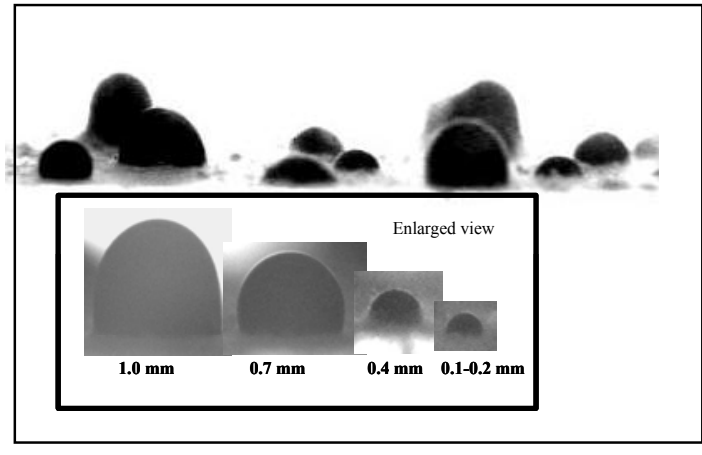

Figure 5. Different sizes of drops (1-0.1 mm ) evolved during wettability experiment.

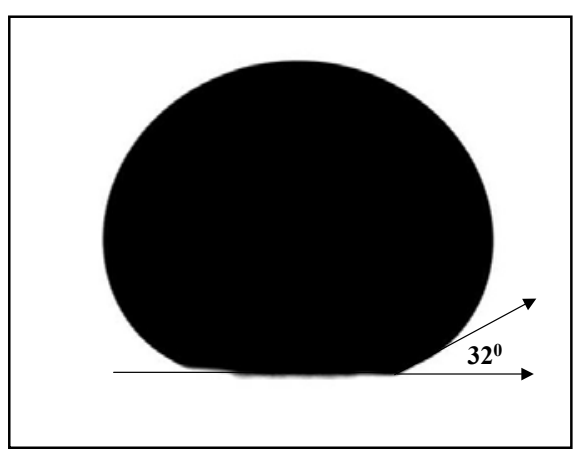

Figure 6. Post-wettability test for Alfoterra-38. 


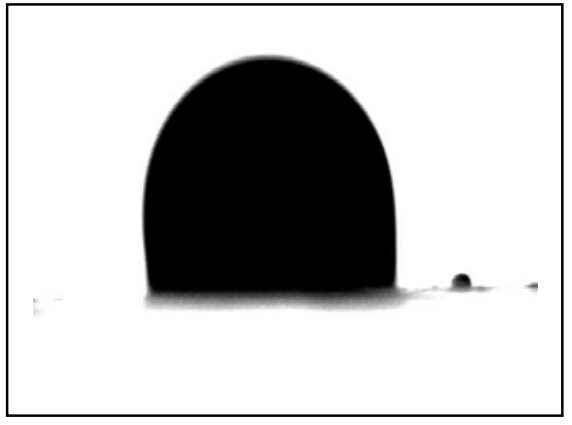

Figure 7. Image of the calcite plate 48 hrs after 1 wt $\%$ DTAB surfactant solution addition.

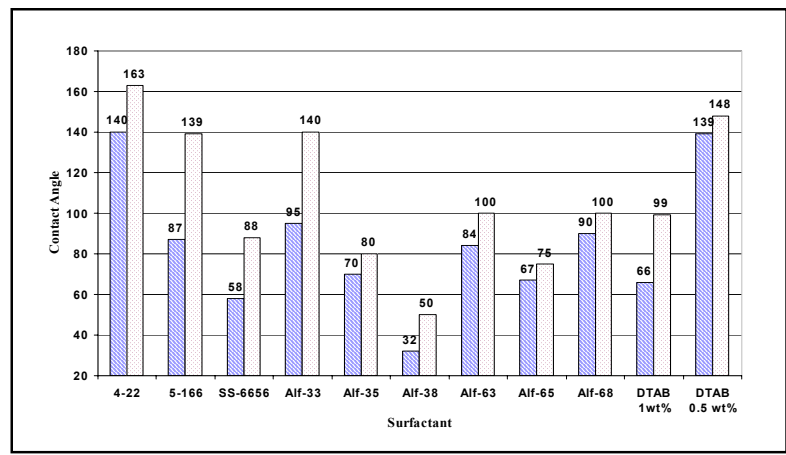

Figure 8. Contact angle at the end of the wettability test. 